\title{
Teatralidade e Antiteatralidade ${ }^{1}$
}

A proposta de reunir alguns textos seminais sobre estes dois termos já exaustivamente abordados nas hostes acadêmicas, seja no campo específico das artes cênicas, seja em áreas próximas das ciências humanas e sociais, parte da convicção de que longe de se terem esgotado as questões que eles propõem para a arte contemporânea em geral, cabe retomá-los para novos exames e sob novas perspectivas. Nesse sentido, os textos que se apresentam aqui têm muito mais um caráter preliminar e sugestivo, para alimentar debates mais amplos, do que uma ambição totalizante.

Ambos os termos, ou conceitos, dependendo esta qualificação do viés de análise que se adote, privam de uma flexibilidade semântica que torna praticamente impossível alcançar uma definição estável para qualquer um deles. De qualquer modo, até pelo que parece haver de produtivo em retomar sua operacionalidade, em tempos em que conceitos como o da "performance art" e da performatividade reivindicam a posição central que eles já ocuparam nos estudos teatrais e candidatam-se a dissolverem-se na mesma generalidade infértil que os desgastou, cabe analisar suas principais facetas, retrospectivamente.

Nesse sentido, confrontam-se dois artigos que poderiam ser considerados clássicos para definir o escopo teórico da ideia de teatralidade - o histórico texto de Bernard Dort, "Representação Emancipada," e a elaboração de Jean-Pierre Sarrazac, em diálogo com o próprio Dort e com a tradição analítica inaugurada por este e por Barthes na revista Théâtre Populaire, "A invenção da 'Teatralidade': relendo Bernard Dort e Roland Barthes". Nunca antes traduzidos para o português, estes dois artigos sintetizam o essencial da discussão que, desde o final dos anos 1950, até o início do ano 2000, mobilizou certa intelectualidade francesa em torno da noção de teatralidade.

\footnotetext{
1 Esse texto incorpora parte da tese de livre docência de Luiz Fernando Ramos, "Mimesis espetacular: a margem de invenção possível", defendida em 2012 a ser brevemente publicada 
Em contraponto, a tradução do também inédito texto de Martin Puchner, "Pânico de Palco: Modernismo, Antiteatralidade e Drama", nos aproxima da tradição anglo-saxônica, apresentada por um de seus intelectuais mais ativos e originais no campo dos estudos dramáticos e teatrais. O texto é a introdução do livro homônimo de Puchner, publicado em 2002, mesmo ano em que o artigo de Sarrazac veio a público na antológica edição da revista Substance sobre a teatralidade, coordenada por Josette Féral. ${ }^{3}$ No livro, o scholar norte-americano se coloca a tarefa de investigar a noção de antiteatralidade, mas não sem estabelecer como ponto de partida a própria genealogia da teatralidade, vista como um valor a ser aceito ou recusado. Puchner demarca em Richard Wagner, e no seu projeto de uma gesamtkunstwerk (obra de arte total), as raízes não só da teatralidade como uma bandeira, como das pulsões antiteatrais que pulularão no drama moderno e, com isso, transforma a antiteatralidade em um interessante conceito operador para se pensar a dramaturgia no século XX.

Considerando que os três textos apresentados foram escritos há mais de uma década, e sem pretender concorrer com sua densidade, caberia aqui, apenas, atualizar de algum modo as questões por eles propostas e colocar alguns problemas que eles não parecem tocar.

Thomas Postlewait e Tracy C. Davis também se detiveram sobre a ideia de teatralidade em livro posterior ao citado volume organizado por Féral. Se os sete capítulos de "Theatricality" apresentam a aplicação do termo para pensar distintos contextos em que a teatralidade e a antiteatralidade podem ser pensadas sob o prisma de contrastes geográficos e históricos, é na introdução que os autores sumarizam o que de mais relevante se escreveu e se pensou sobre estes temas. Particularmente, merecem destaque as suas considerações que ponderam sobre a impossibilidade de qualquer definição absoluta sobre a teatralidade.

\footnotetext{
"Decifrar seus sentidos possíveis tornou-se um desafio maior, e, ocasionalmente, uma impossibilidade, porque essa ideia expandida envolve alguns dos mais urgentes temas de nossa era: aspectos da natureza do espetáculo, a história dos estilos estéticos, os meios e modos de representação, o poder comunicativo da arte e do artista, a formação da subjetividade, e a própria operação da vida pública (da política à vida social). Dados esses sentidos conflitantes é crucial que sejamos capazes de discernir o que se quer dizer quando um escritor utiliza o termo 'teatralidade', mas quase sempre somos confrontados com definições vagas, parâmetros pouco específicos, aplicações contraditórias, e raciocínio tautológico. Consequentemente, o sentido de teatralidade não pode ser tomado como dado." (DAVIS \& POSTLEWAIT, 2003, 2)
}

3 Substance - a review of Theory and Literary Criticism, 98/99 v. 31 n. 2\&3, 2002. 
Se o conceito de teatralidade, como sugerem estes autores, já se provou incapaz de dar conta das complexas relações implícitas na representação espetacular - não só por ter assumido historicamente diversos sentidos, como por ser cativo de uma generalidade desconcertante e carecer de nitidez - no caso da antiteatralidade não é diferente. O mesmo critério que desqualificaria a ideia de teatralidade como operador analítico relevante poderia ser aplicado ao antitético conceito da antiteatralidade.

Interessa-me aqui, em particular, discutir a ideia específica de antiteatralidade como proposta pelo crítico e historiador da arte Michael Fried, que é citada por Puchner em seu texto publicado neste dossiê, mas que, no nosso entender, não é devidamente problematizada por ele. A antiteatralidade implícita no raciocínio de Michael Fried seria uma que teria se manifestado na pintura francesa dos séculos XVIII e XIX, também nomeada como tradição absortiva, e que se desdobraria no projeto da arte modernista, principalmente na pintura norte-americana dos anos 1950, consagrada pelo crítico de artes visuais que de alguma forma ele emula, Clement Greenberg. A questão que se coloca é como conciliar essa perspectiva em Fried, da antiteatralidade tomada como metáfora operativa para que ele se posicione contra o minimalismo, tendência que se manifestava na arte norte-americana no início dos anos 1960 e que estariam, a seu ver, transformando a pintura e a escultura modernas em teatro, com a mesma noção pensada no campo do próprio teatro. Considerando que boa parte da cena moderna e pós-moderna do século XX, como Puchner reconhece, estruturou-se a partir de uma perspectiva fortemente antiteatral, ou pelo menos antimimética e antidramática, a ponto de hoje estar consolidada uma apreciação do teatro contemporâneo como pós-dramático, parece incontornável se perguntar se estaríamos falando aqui da mesma antiteatralidade, e em que medida o argumento de Fried se sustentaria quando comparado com o ponto de vista efetivamente antiteatral da cena contemporânea?

\section{O mal entendido Diderot}

Na perspectiva de Fried, a antiteatralidade residiria no modo da relação ambicionada pela pintura francesa, principalmente no século XVIII, entre as obras e os seus receptores, quando ocorreria um crescente alheamento das figuras e cenas pintadas do eventual observador da tela. Esta tendência se cristalizaria, por exemplo, nas críticas que o filósofo Denis Diderot fez de salões parisienses na década de 1760, em que propunha o ideal de que o observador fosse absorvido pela tela, mergulhando em seus temas e apagando qualquer distância frente a ela. 
Nesta ótica, a fruição seria tanto mais teatral quanto mais a tela se explicitasse de modo inequívoco, impedindo o observador de alhear-se de sua circunstância de fruidor, e tão mais absortiva, ou antiteatral, quanto mais conseguisse atrair a sua atenção, apagando as evidências de que se tratasse de uma pintura.

Caracteriza-se, pois, ali a antiteatralidade como um antídoto, que combate o aspecto percebido como negativo nessa relação, que seria exatamente a consciência das duas partes, tela e fruidor, sobre a circunstância espetacular que os acomete, ou seja, algo se mostra a alguém evidentemente procurando impressioná-lo. Nesse segundo caso, a teatralidade prevaleceria na medida em que a relação do observador com a obra que se dá a ver não só está explicitada, como é tacitamente aceita.

A recusa da teatralidade ou do teatro se configuraria, para Fried, sempre que a tela se constituísse como um plano ficcional capaz de iludir o seu fruidor a ponto de absorvê-lo completamente. Ignorando o projeto de Diderot para o teatro, em que o mesmo dispositivo conceitual é acionado para propor uma cena ilusionista tão potente, a ponto do espectador esquecer-se que está em um teatro, Fried toma a antiteatralidade de Diderot, de fato direcionada contra as a formas artificiais e atemporais do teatro neoclássico francês, ignorando que ela implica num mergulho absoluto na ficção dramática, exatamente aquela que será rejeitada pelas vanguardas históricas no início do século XX e cuja crise e superação será objeto dos criadores mais importantes no teatro dos últimos sessenta anos.

Portanto, o que se considera aqui como antiteatral, em detrimento da visão superficial de Fried sobre o teatro, é a pulsão que nega a narrativa encadeada, ou o próprio dramático. Nesta ótica mais contemporânea, o teatral, que para Michael Fried, talvez, estivesse identificado só com as formas exacerbadas do dramático, como o melodrama, é recusado absolutamente, sempre que acolha e se subordine a qualquer forma de drama, ou mythos. Afeita ao opsis, a interdição antidramática não rejeita a explicitação da mimesis espetacular aos e pelos agentes, mas repele só as mimesis que articulem sentidos fechados, explicitando-se em ações enoveladas. Ela é, portanto, uma antiteatralidade essencialmente antimimética, que assim se diferencia francamente da noção abraçada por Fried.

De algum modo, nos preconceitos históricos contra o teatro, essas duas dimensões antiteatralistas se confundiram. Assim, por exemplo, em Platão, na sua crítica à mimesis espetacular no livro 3 da "República", em que ator e espectador estão cientes 
daquela exposição intencional, a narrativa dramática não encenada, sem atores, é aceita de bom grado. Já no livro 10, em que a mimesis é condenada em absoluto, e qualquer representação, inclusive a enunciação dos aedos, poetas narradores, é descartada como nociva, já há um antimimetismo cristalizado que, em termos contemporâneos, equivaleria a encampar a recusa ao drama, ou à ficção produtora de realidades. Tanto é verdade isto, que contrabalançando a tendência platônica, Aristóteles incidirá sua leitura da tragédia, e da mimesis através dela, favorecendo o mythos contra o opsis e ao mesmo tempo resgatando, além da validade das várias formas de mimesis, a superioridade do drama sobre o espetáculo. Se um espetáculo sem drama, de puro opsis, é potencialmente inferior em suas capacidades de afetação, o antiteatralismo de Aristóteles, se é que se pode projetar essa acepção naquele autor, estaria vinculado à apresentação espetacular despida de sentidos claros.

Essas especulações em torno de um sentido remoto da antiteatralidade, em escritos onde a própria ideia de uma instância conceitual clara para definir a teatralidade só estava latente, justificam-se, apenas, para emoldurar a distinção que interessa aqui esmiuçar no campo antiteatralista, e que se configura propriamente a partir do século XVIII. Michael Fried chamou a atenção dos estudos teatrais, de fato, quando, em 1967, na citada crítica aos minimalistas norte-americanos Donald Judd, Robert Morris e Tony Smith, invocou o conceito de teatralidade e associou-o à disposição daqueles artistas de negar a tradição da pintura e da escultura modernistas. ${ }^{4}$ Chamados também por ele de "literatistas", eles propunham obras despidas de contornos formais reconhecíveis e situadas em ambiente públicos, que se colocavam como objetos indistintos e pretendiam apenas - mais do que afetar em um sentido preciso, gerando leituras consequentes - colocarem-se em relação com os espectadores. Segundo Fried, ao assumirem radicalmente a condição de objeto portada por suas obras, enfatizando-a, eles tornavam literal a tensão implícita, que assombrava principalmente a pintura modernista da época, entre o suporte tela e seu conteúdo pictórico.

Fried expressou sua ojeriza a essa tendência, que nomeou de teatral, definindo três proposições que sintetizavam os impasses da pintura e da escultura modernistas naquele momento. A primeira era que o sucesso, ou mesmo a sobrevivência das artes, dependeria de suas habilidades de derrotarem o teatro. A segunda corroborava a primeira, afirmando que a arte se degenerava quando se aproximava da condição de

4 Fried, Michael, Art and Objecthood: essays and reviews, Chicago, University of Chicago Press, 1988, pp. 148-172. 
teatro. E a terceira, convergente com as duas anteriores, postulava que os conceitos de qualidade e valor, e a própria conceituação da arte, só faziam sentido pensados dentro de cada uma das artes, tomadas individualmente. Segundo Fried o que está 'entre' as artes é exatamente o teatro, território da linguagem que careceria de especificidade. Mais tarde, o próprio Fried, quando publicou seu estudo sobre a pintura francesa em que identificava pioneiramente a já citada tendência antiteatralista nos pintores e críticos da época, deixou claros a fonte e o sentido do uso que fez da ideia de antiteatralidade. ${ }^{5}$ Ele examinou a pintura e a crítica de arte no século XVIII francês minimizando a relação das críticas de Diderot aos pintores contemporâneos, em que se manifestaria a projetada tendência absortiva, com as propostas do filósofo para a reforma da cena francesa do mesmo período, expressas no "Discurso sobre a Poesia Dramática"6. Mesmo considerando o desinteresse do historiador e crítico pelo teatro, manifesto no uso superficial que faz do legado de Brecht e Artaud em seu favor no famoso artigo de 1967, não deixa de ser curioso que um elemento aparentemente decisivo para a consecução de seu raciocínio - um mesmo programa ilusionista para a pintura e o teatro setecentistas - fosse tão pouco enfatizado. Se essa aproximação está implícita nos argumentos de Fried, ainda que ameace suas bases, não pontuá-la é o primeiro indício de que há algo forçado na sua conclusão.

Como já se disse, quando Diderot escreveu o seu "Discurso sobre a Poesia Dramática", ele criticava uma leitura de Aristóteles e de sua "Poética" que tinha sido consumada e difundida no século anterior. A perspectiva neoclássica consagrou um aristotelismo dogmático, que pregava unidades imprescindíveis - tempo, lugar e ação - e torcia a ideia de verossimilhança em conveniência e decoro, transformando o que era uma necessi-

\footnotetext{
5 A par das polêmicas geradas no âmbito da crítica de arte, e da repercussão periférica entre os estudos teatrais voltados ao conceito de teatralidade, pouco se investiu nesse meio na compreensão do que, afinal, Fried entendia por teatralidade, e em que medida a utilização do conceito por ele era mais do que acessória, partindo do senso comum, e superficial. Uma exceção é o artigo de Anne-Britt Gran na coletânea "Teatralidade", organizada por Josette Féral ("The Fall of Theatricality in the Age of Modernity", in Substance, 98/99 vol. 31 nos. 2 \& 3, 2002, pp 251-264) Gran sustenta - aceitando que o drama realista proposto por Diderot era antiteatral e coincidente com seu programa ilusionista para as artes plásticas - que Fried faz um uso legítimo do conceito ao sobrepor sua crítica aos minimalistas nos anos sessenta aos seus estudos da pintura francesa no século 18. Foi ali que Fried identificou a suposta tendência antiteatral, por projetar um espectador absorto, neutralizado e esquecido pela tela. As duas obras pois que constituem a base do raciocínio de Fried são o citado artigo "Art and Objecthood" de 1967 e o livro Absortion and Theatricality -Painting and beholder in the Age of Diderot, de 1980.

60 discurso é citado de passagem, mas Fried não se preocupa, por exemplo, em aprofundar a sincronia entre a ideia de absorção na pintura à proposta diderotiana para o teatro, em que está implícita a ideia de uma quarta parede imaginária entre o espetáculo e os espectadores.
} 
dade pragmática de eficácia da ilusão em regras inexpugnáveis de caráter moralizante. Além disso, contra a ideia de um teatro essencialmente fundado na enunciação literária, alijado da realidade cotidiana e projetado nas alturas idealizadas da cultura clássica, Diderot proporá uma cena que reflita o dia a dia urbano e seus elementos básicos, como o núcleo familiar burguês, e o faça a partir da assunção dos aspectos materiais do teatro, como os corpos dos atores, seus movimentos e ritmos, assumidos como constituintes da linguagem cênica. Ciente dos aspectos dinâmicos do desempenho dos atores na Commedia Dell'arte, por exemplo, ele os empresta a fim de dotar essa nova cena de verossimilhança e aumentar-lhe a sua capacidade de espelhar a realidade. Só assim, a finalidade desse drama, qual seja, a afetação máxima dos espectadores a ponto deles esquecerem que assistiam a um espetáculo, seria alcançada. Com cem anos de antecedência, Diderot teoriza e propõe a ideia de uma quarta parede, que o teatro naturalista adotará como padrão. Só com esse grau de ilusão obtido, o efeito das fábulas apresentadas sobre o público permitiria seu deleite e propiciaria seu aperfeiçoamento moral. Da mesma forma, o próprio Fried informa o quanto Diderot valoriza pintores como Vernet e Loutherbourg pela sua habilidade de, em suas telas com paisagens naturais, criarem a ilusão dramática de uma "necessidade causal da natureza". Como já se explicitou aqui, antes de ser antiteatral, como Fried sugere, a tese absortiva de Diderot, tomada tanto na pintura, como no teatro, é profundamente dramática, cúmplice da ideia aristotélica de mimesis e, consequentemente, do teatral enquanto instância representacional subordinada ao mythos. $\mathrm{O}$ ataque de Diderot à teatralidade refere-se à tradição teatral neoclássica, profundamente hierática e formalizada. Sua disposição não é contra o teatro como drama, mas contra o caráter inócuo e artificial que uma teatralidade distante da realidade histórica do século XVIII, como a da tragédia neoclássica oferecia. A melhor prova disso é a oposição que seu contemporâneo Rousseau lhe fará na apreciação ao teatro. ${ }^{8}$ Se as restrições deste são totais, associadas tanto ao caráter espetacular, como aos artifícios dramáticos implícitos, Diderot prefere restringir sua crítica, ou sua antiteatralidade, às deficiências representacionais de certo modo de encenação, em favor do resgate da eficácia dramática na capacidade de iludir e, assim, de afetar de forma sub-reptícia o público, inclusive obrando pela sua elevação moral. Seu projeto antecipa o naturalismo, naquilo em que este procura disfarçar ou minimizar os aspectos

\footnotetext{
7 Fried, Michael, Absortion and Theatricality - Painting and Beholder in the Age of Diderot, Chicago \& London, 1988, p 132, nota 52, p,228,. nota 52,.

8 Ver Rousseau, Jean-Jacques, Carta a D’Alembert, in Oeuvres, vol.2, Paris, 1823-26) pp21-45.
} 
explícitos da teatralidade, mas não configura uma oposição ao teatro e muito menos à dimensão dramática e seu poder persuasivo de iludir, ou absorver o espectador numa narrativa ficcional, como ocorre, ao contrário, na rejeição contemporânea ao dramático. O sentido positivo da mimesis na mirada aristotélica, seu poder cognitivo e o prazer a ele associado, é resgatado, tornando impossível perceber nesse programa diderotiano uma antiteatralidade de fato, pelo menos não a que se configura depois de Wagner, na crítica que Mallarmé e Nietzsche lhe fazem, como o próprio Puchner reconhece.

Se concordarmos com Anne-Britt Gran, que cada época histórica inventou sua percepção sobre a teatralidade, "sua mitologia", como sugere $^{9}$, o teatro da segunda metade do século XX, claramente, leria uma proposta como a de Diderot como profundamente dramática, na medida em que pressupõe uma cena com toda sorte de artifícios construtivos para ocultar a condição material, ou objetual - como preferiria Fried - do teatro, e, assim, afetar os espectadores. Na ótica aqui aplicada, de identificar o antiteatral com o antidramático, não resta dúvida que Diderot estava essencialmente alinhado ao dramático e, consequentemente, à teatralidade.

É certo que, na primeira metade do século XX, Evreinov, Meyerhold e o próprio Brecht propuseram a reteatralização do teatro, exatamente contra a tendência naturalista de algum modo inaugurada por Diderot. Mas esta proposta de combater o ilusionismo com a exacerbação da teatralidade não se confunde com a tradição antiteatralista que se define pela recusa ao dramático. Na perspectiva de Mallarmé, ou de Beckett e Robert Wilson, o teatro não deve ser ilusão ficcional, mas fricção da matéria visual bruta que se apresenta contra a realidade que a acolhe, ainda que no caso do poeta francês esse contraste ainda estivesse contaminado por uma dimensão idealista e metafísica. O teatro contemporâneo, nas formas que foram chamadas de pós-dramáticas, não é definitivamente absortivo, repele o ilusionismo e busca a autonomia diante do espectador, ao mesmo tempo libertando-o a constituir sua própria independência. Nos termos de Fried, certo teatro contemporâneo é pura arte e derrotou o teatro. Nesse sentido, fica evidente o quanto a assimilação da leitura de Diderot como antiteatral, e a oposição de uma prática absortiva, essencialmente dramática, à teatralidade é desencaminhadora. Talvez o que Fried esteja querendo dizer, quando fala em teatralidade como associada ao drama e à mimesis efetivada, é, ao contrário, defender o dramático contra o espetacular, exatamente na contramão da corrente antiteatralista

9 Gran, op.cit. p.251 
como está aqui sendo considerada. Em contrapartida, há que se reconhecer, Fried foi profético quando percebeu, ainda nos anos 1960, que a arte pós-minimalista seria crescentemente teatral, no sentido de cada vez mais depender de um público ativo e consciente de sua condição de coautor das obras, como as instalações contemporâneas claramente atestam.

Nos últimos anos, os estudos literários e teatrais se voltaram para a questão da antiteatralidade e muito se escreveu a respeito, só exacerbando o contraste entre uma postura como a de Fried e outras diametralmente opostas, que partem de questões do próprio campo teatral e comprovam a relevância do tópico na contemporaneidade.

Martin Puchner foi um dos responsáveis por impulsionar esse debate com seu já citado livro, cuja introdução está aqui publicada, em que destaca as resistências filosóficas e artísticas às ideias e projeto estético implícitos à ópera de Richard Wagner. ${ }^{10}$ Em outro volume mais recente - "Against Theatre - creative destructions on the modernist stage" editado pelo próprio Puchner e por Alan Ackerman, amplia-se o foco na antiteatralidade para diversos campos e períodos históricos. Um capítulo em especial, "Anti-Theatricality and the limits of Naturalism", merece ser aqui destacado, não só pela sua qualidade intrínseca, mas pelo fato de elucidar com grande eficácia o próprio tema da antiteatralidade. O autor, Kirk Williams, parte do trabalho pioneiro de Jonas Barish, "The Anti-Theatrical Prejudice"11 em que este percebe a antiteatralidade como um tropo específico do próprio teatro que é "dependente de forma parasitária da representação teatral"12, ou, como complementa Williams, torna-se "a razão e ser do próprio teatro."13 É para desenvolver essa tese que o autor elege o movimento naturalista, particularmente na sua expressão alemã nas últimas décadas do século XIX. Ali se objetivava remover completamente as barreiras separando o teatro da vida, "para criar uma ilusão tão poderosa que tornaria o meio teatral absolutamente transparente." Abordando as peças de dramaturgos como Gerhart Hauptmann,

10 O próprio Puchner, em obra mais recente, avança na discussão e retoma o debate sobre o antiteatralismo de Platão, discutindo como sua filosofia foi engendrada por meio de estratégias dramáticas e percorrendo, na história da filosofia e do drama, como dramaturgos produziram dramas de extração filosófica e os filósofos, filosofias com recursos dramáticos. Puchner, Martin, The Drama of ideas -platonic provocations in theater and philosophy, Oxford, Oxford University Press, 2010.

11 Barish, Jonas, The anti-theatrical prejudice, Berkeley, Universiy of Califórnia Press, 1981.p.85

12 Barish. Op.cit. p.85, apud Kirk Willians. Anti-Theatricality and the limits of Naturalism"in Ackerman \& Puchner "Against Theatre - creative destructions on the modernist stage, New York, Palgrave Macmillan, 2006, pp95-111.

13 Williams. Op.cit.p 96. 
e do grupo de criadores reunidos sob a liderança de Otto Brahm e seu teatro, o Freie Buhne (palco livre), Williams detecta uma "histericização do espaço cênico", provocada, por exemplo, em "Os Tecelões" de Hauptmann, pelo contraste entre o apagamento nos corpos dos operários retratados de qualquer metáfora, e a profusão de detalhes cenográficos naturalistas, que constituiriam "um retorno histérico do reprimido, um suplemento compensatório para criar, paradoxalmente, uma atmosfera de verdade e transparência." ${ }^{14}$ Sem prosseguir no detalhamento dessa análise, estrita ao naturalismo alemão, vale pinçar uma observação genérica de Williams que interessa à discussão aqui proposta em torno da antiteatralidade e que caracteriza bem um olhar diametralmente oposto ao que se percebe, por exemplo, na posição de Michael Fried. Comentando os aspectos morais e ideológicos que perpassaram o projeto naturalista na sua generalidade, Williams descreve o que chama de "fantasia pós-teatral" e localiza historicamente o realismo socialista na União Soviética como aquele que levou o naturalismo ao seu “(ilógico) extremo".

\footnotetext{
"A ironia deste teatro pós-teatral é que não pode nunca ser mais que um retorno à alegoria. Naturalismo, no seu limite, pode apenas tornar alegórica sua própria impossibilidade, assim provando que o teatro revela-se mais teatral que nunca, mais metafórico, quando tenta transcender suas próprias condições de representação" (ACKERMAN \& PUCHNER, 2006, p.101)
}

O comentário é precioso exatamente porque coloca com clareza o paradoxo do projeto realista/naturalista e dos artifícios que tem de lançar mão para se realizar. Cabe, pois, remetê-lo também à questão da antiteatralidade em exame, tanto no que fragiliza a posição de Fried e seu encantamento pelo idealizado naturalismo diderotiano quanto no que encaminha uma outra discussão, que não caberia aqui desdobrar, aproximando as noções de anti-teatralidade e de antimimetismo.

\section{Referências Bibliográficas}

ACKERMAN, Alan \& PUCHNER, Martin (eds.), "Against Theatre - Creative destructions on the Modernist Stage", New York, Palgrave MacMillan, 2006.

DAVIS C., Tracy C. \& POSTLEWAIT, Thomas (eds.), "Theatricality", Cambridge, Cambridge University Press, 2003.

OLIVEIRA M.,Feranando, " Teatralidades - 12 percurssos pelo território do Espetáculo", Ângelus Novus, Coimbra, 2003.

PUCHNER, Martin, "The Drama of Ideas - platonic provocations in theater and philosophy", Oxford, Oxford University Press, 2010.

14 Op.cit. p. 105 